Copeland, J. R. M., Dewey, M. E. and Griffith-Jones, H. M. (1986). A computerised psychiatric diagnostic system and case nomenclature for elderly subjects: GMS and AGECAT. Psychological Medicine, 16, 8999.

Ferri, C. P. et al. (2005). Global prevalence of dementia: a Delphi consensus study. Lancet, 366, 2112-2117.

Ganguli, M., Chandra, V. and Gilbey, J. (1996). Cognitive test performance in a community-based non demented elderly sample in rural India: the Indo-US cross national dementia epidemiology study. International Psychogeriatrics, 8, 507-524.

Hall, K. S. et al. (1993). The development of a dementia screening interview in two distinct languages. International Fournal of Methods in Psychiatric Research, 3, 1-28.

Prince, M., Acosta, D., Chiu, H., Scazufca, M. and Varghese, M. (2003). Dementia diagnosis in developing countries: a cross-cultural validation study. Lancet, 361, 909-917.

\author{
Nazbanou Nozari, ${ }^{1}$ Cleusa P Ferri, ${ }^{2}$ \\ FARANEH FARIN, ${ }^{3}$ MARYAM NOROOZIAN, ${ }^{4}$ \\ Masomeh Salehi, ${ }^{3}$ Maziar Seyedian ${ }^{4}$ \\ AND MARTIN PRINCE ${ }^{2}$ \\ ${ }^{1}$ Beckman Institute, University of Illinois, Urbana, \\ Illinois, USA \\ ${ }^{2}$ Institute of Psychiatry, HSPR, Kings' College \\ London, U.K. \\ ${ }^{3}$ Iran Alzheimer's Association, Tehran, Iran \\ ${ }^{4}$ Tehran University of Medical Sciences, Tehran, Iran, \\ Email: nazbanou.nozari@gmail.com and \\ c.ferri@iop.kcl.ac.uk
}

\section{The contribution of elderly suicide rates of the three consituent countries of the United Kingdom to the overall national suicide rate}

We recently reported age-associated suicide rates and trends over time for elderly suicide rates for the whole of the U.K. and its three constituent countries (England and Wales, Scotland and Northern Ireland) (Shah and Coupe, 2009). That study, in part, was conducted to examine the impact of the suicide prevention policies for each of the three constituent countries as the governmental suicide reduction targets for 2010, 2011 and 2013 move closer for England, Northern Ireland and Scotland respectively.

Each of the three constituent countries has developed its own national suicide prevention strategy. The governmental initiative Health of the Nation (Department of Health, 1992) set a target to reduce the suicide rate by $15 \%$ by 2000 in England. A subsequent initiative, Saving Lives: Our Healthier Nation (Department of Health, 1999), set a further target to reduce the suicide rate by at least $20 \%$ by 2010 in England. This was supported by the National Suicide Prevention Strategy for England (Department of Health, 2002). A suicide prevention action plan for Wales is currently being developed (Welsh Assembly Government, 2008). The national suicide prevention strategy Choose Life for Scotland (Scottish Executive, 2002) is a 10 -year plan with a target reduction of $20 \%$, from 17.4 per 100,000 , to be reached by 2013. In Northern Ireland, the national suicide prevention strategy was initially implemented through the Promoting Mental Health strategy (Department of Health, Social Services and Public Safety Northern
Ireland, 2003) and subsequently enhanced by a separate suicide prevention strategy Protect Life (Department of Health, Social Services and Public Safety Northern Ireland, 2006) with the aim of reducing the overall suicide rate by $10 \%$ by 2008 with a further reduction of $5 \%$ by 2011 .

If the impact and relative contribution of the suicide prevention strategies for each of the three constituent countries on the overall elderly suicide rates for the U.K. is to be evaluated then it would be important to examine the contribution of elderly suicide rates in each of the three constituent countries to the overall elderly suicide rates in the U.K.

Data on suicide rates in the age-bands 6574 years and $75+$ years for both sexes in the U.K. and the three constituent countries were ascertained from the WHO website (www.who.int/ whosis/database/mort/table1_process.cfm) for each of the 24 years from 1979 to 2002. Multiple regression analysis with the Enter method was used to examine the relative contribution of each of the three countries to the time trends in elderly suicide rates for the whole of the U.K. for both sexes; elderly suicide rates for the whole of the U.K. was the dependent variable and the suicide rates for each of the three constituent countries, the elderly population size for the whole of the UK and each of the three constituent countries were the independent variables. The WHO website (www. who.int/whosis/database/mort/table1_process.cfm) provided data on the elderly population size. Elderly population size was included as an independent variable because there is previous evidence of a positive correlation between elderly population size and elderly suicide rates (Shah et al., 2008a), a positive correlation between elderly dependency ratios and elderly suicide rates (Shah et al., 
2008b), and the elderly population size of the three consituent countries was significantly different.

On multiple regression analysis, the suicide rate among males in the age-band $65-74$ years in the whole of the U.K. was significantly predicted by suicide rates in males in the age-band 6575 years in England and Wales $(\mathrm{P}<0.00001)$, Scotland $(\mathrm{P}<0.00001)$ and Northern Ireland $(\mathrm{P}<0.00001)$. The findings were identical for suicide rates in males in the age-band $75+$ years and females in the age-band 65-74 years. However, suicide rates in females in the age-band $75+$ in the whole of the U.K. was only significantly predicted by suicide rates in females in the age-band $75+$ for England and Wales $(P=0.01)$.

There is a differential effect of gender and elderly age-band from each of the three constituent countries to the overall elderly suicide rates in the U.K. This finding needs to be considered in the interpretation of the impact of the suicide prevention strategies of the three constituent countries on the elderly suicide rates for the whole of the U.K.

\section{References}

Department of Health (1992). Health of the Nation: A Strategy for Health in England. London: HMSO.

Department of Health (1999). Saving Lives: Our Healthier Nation. London: HMSO. Available at: www.archive.officaldocuments.co.uk/document/cm43/4386/4386.htm; last viewed 11 August 2008.

Department of Health (2002). National Suicide Prevention Strategy for England. Available at: www.dh.gov.uk/en/ Publicationsandstatistics/Publications/ PublicationsPolicyAndGuidance/DH_4009474; last viewed 26 June 2008.

Department of Health, Social Services and Public Safety Northern Ireland (2003). Promoting Mental Health,

doi:10.1017/\$1041610209008898

\section{Aggressive behavior by patients and its relationship to nursing staff attitudes and perceptions}

Continuing care old age psychiatry units often have high levels of behavioral disturbance. Shah (1999) reported that levels of aggressive behavior can be influenced by several factors including patient variables, patterns of hospital use and the nature of the ward environment. The ward environment includes variables such as staffing levels, staff attitudes and perceptions, staff morale and the character of staff-patient interaction. The
Strategy E Action Plan 2003-2008. Available at http://www. dhsspsni.gov.uk/publications/2003/promoting_mental_ health.pdf; last viewed 28 July 2008.

Department of Health, Social Services and Public Safety Northern Ireland (2006). Protect Life. A Shared Vision. The Northern Ireland Suicide Prevention Strategy and Action Plan 2006-2011. Available at: http://www.dhsspsni.gov.uk/ phnisuicidepreventionstrategy_action_plan-3.pdf; last viewed 28 July 2008

Scottish Excecutive (2002). Choose Life. A National Strategy and Action Plan to Prevent Suicide in Scotland. Edinburgh: The Stationery Office.

Shah, A. K. and Coupe, J. (2009). A comparative study of elderly suicides in England and Wales, Scotland and Northern Ireland: trends over time and age-associated trends. International Psychogeriatrics, 21, 1-7.

Shah, A. K., Bhat, R., MacKenzie, S. and Koen, C. (2008a). Elderly suicide rates: cross-national comparisons of trends over a 10-year period. International Psychogeriatrics, 20, 673-686.

Shah, A. K., Padayatchi, M., Das, K. (2008b). The relationship between elderly suicide rates and elderly dependency ratios: a cross-national study using data from the WHO data bank. International Psychogeriatrics, 20, 594-604.

Welsh Assembly Government (2008). Suicide. Written Statement by the Welsh Assembly Government. Available at: http://www.new.wales .gov.uk/caec/report/ cabinetstatements/2008/suicides/statement.e.doc?lang=en; last viewed 7 August 2008.

\author{
AJIT SHAH ${ }^{1}$ AND JACQUELINE COUPE ${ }^{2}$ \\ ${ }^{1}$ Professor of Ageing, Ethnicity and Mental Health, \\ International School for Communities, Rights and \\ Inclusion, University of Central Lancashire, Preston, \\ U.K. and Consultant Psychiatrist, West London \\ Mental Health NHS Trust, London, U.K. \\ ${ }^{2}$ Student Intern, International School for \\ Communities, Rights and Inclusion, University \\ of Central Lancashire, Preston, U.K. \\ Email: ajit.shah@wlmht.nhs.uk
}

relationship between aggressive behavior and the nature of the ward environment has been less well studied. We carried out a study to examine the relationship between aggressive behavior by patients, nursing staff attitudes and perception and stress amongst nurses. We report findings from our study on the relationship between aggressive behavior by patients on old age psychiatry wards, nursing staff attitudes and perceptions.

Ethical approval for this study was granted by the local Ealing Research Ethics Committee. The study was carried out over a three-month period, on two 16-bed old age psychiatry wards on the John Conolly Wing, St Bernard's Hospital, serving a catchment area of 40,000 older people. All patients 